Bond University

Research Repository

\title{
:
}

\section{Effects of Sex and Age on Physical Testing Performance for Law Enforcement Agency Candidates: Implications for Academy Training: Implications for Academy Training}

\author{
Bloodgood, Ashley M; Dawes, J Jay; Orr, Robin M; Stierli, Michael; Cesario, Karly A; Moreno, \\ Matthew R; Dulla, Joseph M; Lockie, Robert G \\ Published in: \\ Journal of Strength and Conditioning Research
}

DOI:

10.1519/JSC.0000000000003207

Licence:

Other

Link to output in Bond University research repository.

Recommended citation(APA):

Bloodgood, A. M., Dawes, J. J., Orr, R. M., Stierli, M., Cesario, K. A., Moreno, M. R., Dulla, J. M., \& Lockie, R. G. (2021). Effects of Sex and Age on Physical Testing Performance for Law Enforcement Agency Candidates: Implications for Academy Training: Implications for Academy Training. Journal of Strength and Conditioning Research, 35(9), 2629-2635. https://doi.org/10.1519/JSC.0000000000003207

\section{General rights}

Copyright and moral rights for the publications made accessible in the public portal are retained by the authors and/or other copyright owners and it is a condition of accessing publications that users recognise and abide by the legal requirements associated with these rights.

For more information, or if you believe that this document breaches copyright, please contact the Bond University research repository coordinator. 
The Effects of Sex and Age on Physical Testing Performance for Law Enforcement Agency Candidates: Implications for Academy Training 


\section{ABSTRACT}

Law enforcement candidates are often required to complete fitness tests to assess their preparedness for training. This study investigated the influence of sex and age on candidate performance prior to academy training. Retrospective analysis of 516 candidates was performed. Data were stratified into males $(n=432)$ and females $(n=84)$ and the pooled (males and females combined) data was stratified into age groups $(20-24 ; 24-29 ; 30-34 ; 35-39 ; 40+$ years $)$. The tests included: maximal push-ups and sit-ups in $60 \mathrm{~s}$; 75-yard pursuit run (75PR); arm ergometer revolutions completed in $60 \mathrm{~s}$; and a $2.4-\mathrm{km}$ run. To compare the sex and age groups, a 2 x 5 ANOVA (with Bonferroni post hoc for multiple between-age group comparisons) was used. Males performed significantly $(p<0.001)$ more push-ups, sit-ups, and arm ergometer revolutions, and were faster in the 75PR and 2.4-km run. The 20-24, 25-29, and 35-39 year groups were faster in the 75PR compared to the 40+ year group; the 20-24 and 25-29 year groups were faster than the 35-39 year group; and the 20-24 year group was faster than the 30-34 year group $(p \leq 0.023)$. The 20-24 year group was faster than the $40+$ year group in the $2.4-\mathrm{km}$ run $(p=0.005)$. Females and older candidates may have a lower physical capacity than males and younger candidates, respectively, in certain physical assessments. Female and older candidates, in particular, may benefit from dedicated training prior to academy in order to better prepare for the demands of this period.

Key words: agility; arm ergometer; police; push-ups; sit-ups; tactical; 2.4-km run 


\section{INTRODUCTION}

The law enforcement profession can require officers to perform tasks of significant physiological demand (i.e. lifting or dragging an object or person, using force, or engaging in a foot pursuit) (4). Even law enforcement tasks that could be outwardly viewed as low-intensity could elicit an intense physiological response (e.g. driving or attending to a domestic incident) can result in heart rates equivalent to high-intensity exercise (17). As a result, law enforcement agencies (LEA) conduct testing to assess the physical fitness attributes of candidates that relate to the demands of the occupation $(4,15)$, and to identify whether candidates have the physical qualities (e.g. anaerobic and aerobic capacity) necessary to successfully complete and graduate academy (42). Some examples of tests used to evaluate these underlying characteristics include maximal push-ups and sit-ups to measure muscular strength-endurance; an arm ergometer test to assess upper-body endurance; linear or change-of-direction speed tests; and a 2.4-kilometer (km) or 1.5-mile run to assess aerobic capacity $(4,31)$. Physical fitness assessments are not state mandated for LEAs. However, each agency may have their own physical fitness requirements and should be consulted directly for information specific to that LEA (11).

LEAs typically have a non-discriminatory hiring policy in regards to candidate age, sex, and ethnicity for all qualified individuals (32). While LEAs should use physical tests that do not differ according sex, when these tests are employed as a measure of occupational capability (3, 38), or survivability of training (37), there could still be differences in the performance of male and female candidates. Performance standards do not differ based on gender for physical tests. Both male and female recruits are required and expected to meet the same minimum physical qualifications due to the demands of the job being the same, regardless of gender (32). Differences in physical performance between the sexes have been well established in the literature $(2,6,13$, 
16, 29). Boyce et al. (6) found that incumbent male officers demonstrated greater upper-body strength measured by the a one-repetition maximum (1RM) bench press in both initial recruitment and in-service testing, and female officers only had $44 \%$ of the upper body strength of their male counterparts. Lockie et al. (29) found that male recruits outperformed females in the medicine ball throw and vertical jump as tests of upper- and lower-body power, respectively. The disparity in strength and power between males and females can in part be attributed to the propensity for skeletal muscle in males to be $36 \%$ greater than that for females (22). Further, Dawes et al. (16) found that male officers had a higher predicted maximal aerobic capacity $\left(\mathrm{VO}_{2}\right.$ max $)$ when compared to females measured by a 20-meter (m) multi-stage fitness test (MSFT). The sex differences in $\mathrm{VO}_{2}$ max could be expected due to males having greater skeletal muscle mass (22), which could contribute to superior power and work efficiency in aerobic tasks compared to females (39). Accordingly, females that pass initial baseline recruitment testing for an LEA may still be less fit, in general, than their male counterparts undergoing academy.

Age may also be a factor in the performance of law enforcement candidates, as physiological characteristics relating to strength, power and speed tend to decline with age (27). Specific to incumbent law enforcement officers (LEOs), Lockie et al. (31) found that there were significant differences in vertical jump height and power, maximum repetition sit-ups in $60 \mathrm{~s}$, and 2.4-km run times in officers when they were grouped by age decades, with older officers (40-49 and 50-59 year age groups) performing worse on these measures than their younger counterparts (20-29 and 30-39 year age groups). In female officers, Lockie et al. (31) found no differences for vertical jump height and power, but they did discover significantly lower scores in maximum pushup repetitions among older female officers. Anderson et al. (1) found that older age ( $\geq 28$ years) for men had a negative effect on all physical tests, except push-ups, during individual physical 
training in the military. Additionally, incoming recruits to a LEA aged 35 years or older tended have lesser performance in both the medicine ball throw and vertical jump when compared to younger recruits (29). These findings are not unexpected given both males and females from the general population experience a decline in the quantity of their skeletal muscle (22). With regards to LEA candidates, this difference in skeletal muscle quantity may possibly result in older candidates having poorer performance, in general, than younger candidates.

Despite the influence of sex and age on the physiology of a LEO, the physical job characteristics remain the same for most officers (13). Due to the physical demands of law enforcement, it is standard for LEAs to utilize physical training programs to assist incoming candidates to develop the physical attributes required for their jobs $(9,36)$. Previous research has shown that an appropriate conditioning program for academy training can enhance physical fitness as measured by maximal number of push-up and sit-up repetitions, 1RM bench press, and 300-m and 2.4-km run time (9). However, a potential issue for candidates is that they may have a higher risk of injury as a result of lower levels of fitness prior to entering the academy (18), and may be exacerbated by the sex and age of the candidate. This could be especially problematic if training staff do not recognize fitness differences between candidates, and program purely based on a model that expects all candidates to perform the same training (36). Although there is previous research that investigates the effects of sex and age on physical fitness in certain law enforcement populations $(3,29,40,45)$, there is limited research that has analyzed those characteristics of LEA candidates prior to the start of academy training or as part of the hiring process. This analysis is needed to document potential fitness differences in candidates prior to academy, and to highlight that programming via a 'one-size-fits-all' model may not be appropriate (36). 
Therefore, the aim of this study was to investigate the effects of sex and age on physical fitness assessment performance of LEA candidates prior to the start of their academy training. It was hypothesized that male and younger candidates would perform better than the females and older candidates, respectively.

\section{METHODS}

\section{Experimental Approach to the Problem}

A retrospective analysis of existing data was performed to investigate the effects that sex and age had upon physical testing performance in successful candidates to a LEA. In the context of this study, a successful candidate was one who had the requisite physical abilities to be accepted to an academy class. Physical fitness testing occurred on one day for each recruit class, within the span of one year prior to entering academy training. Data were stratified by sex (males and females), and the pooled (males and females combined) was also stratified into different age groups: 20-24 years; 24-29 years; 30-34 years; $35-39$ years; and $40+$ years. These age groups have been utilized in previous law enforcement research, and thus were adopted in this study $(16,31)$. Recruits above 40 years of age were grouped together to allow for a more robust analysis in this study. A series of independent samples t-tests were used to compare the sexes, while a one-way analysis of variance (ANOVA) was used to compare the candidates by age. The dependent variables for this study were: age, height, and body mass; push-up and sit-up repetitions; 75-yard pursuit run (75PR) time; number of revolutions in the arm ergometer test; and 2.4-km run time.

\section{Subjects}


Data were collected by the staff of a state LEA in the USA during the initial recruitment process and was released with consent from that organization. A sample of convenience comprised of 516 successful applicants to the LEA (age: $27.34 \pm 6.10$ years; height: $1.74 \pm 0.09$ m; body mass: 80.26 \pm 13.12 kilograms $[\mathrm{kg}])$, which consisted of 432 males and 84 females. The characteristics of the subjects in this study were similar to that from other research on law enforcement recruits $(29,30)$. In addition to this, the ratio between the sexes was typical of law enforcement populations $(6,9$, 16, 29, 31, 42). Subjects were wearing mandated LEA athletic attire which consisted of running shorts and cotton short-sleeved shirts. Tests were conducted from 0800-1400. The dress and time of day were consistent across all subjects with ambient temperatures being characteristic of Southern California during the calendar year. No formal nutritional guidelines or recommendations were made prior to, or as part of, testing. Based on the archival nature of this analysis, the institutional ethics committee approved the use of pre-existing data.

\section{Procedures}

The data in this study were collected by the staff of one LEA in the order, and the following procedures, detailed in this section. The LEA staff were all trained and proficient in conducting the required assessments. The push-up and sit-up tests, 75PR, and arm ergometer test were conducted outdoors on a concrete surface at the training facility for the LEA. The $2.4 \mathrm{~km}$ run was performed with candidates at an outdoor running track at the facility. Trials per tests were standardized for all recruits regardless of sex or age (32). Standards for passing are determined internally at the agency according to a composite of the scores, and the researchers have no influence on this data. Testing occurred prior to the start of academy during scheduled LEA recruitment days. Recruitment days allow for the general public who are interested in applying to 
speak with LEA staff and complete a written exam prior to completing a physical fitness assessment.

\section{Push-up Test}

The 60-s maximal push-up test assessed upper-body strength endurance $(13,14,31)$, which is of importance when LEOs have to drag an object or suspect, or forcibly restrain an inmate $(4,31)$. Candidates started in the standard 'up' position, with the body taut and straight, the hands positioned shoulder-width apart, and the fingers pointed forwards. Staff at the LEA utilized a standard water bottle to determine the bottom position of the push-up, which was positioned underneath the candidate's chest (32). On the start command, a LEA staff member began the stopwatch, and candidates flexed their elbows, lowered themselves until their chests contacted the water bottle, and extended their elbows to return to the start position. The candidates performed as many push-ups as possible using this technique in the allotted $60 \mathrm{~s}$ time period during one trial. Candidates could rest in the up position with elbows locked, but only full repetitions were recorded.

\section{Sit-up Test}

The 60-s sit-up test was used to assess abdominal muscle endurance $(16,30,31)$. Sit-up performance could be indicative of strong abdominal muscles (31), and stronger abdominal muscles are conducive to enhanced strength and power performance (35). Candidates laid on their backs on padded mats with their knees flexed to $90^{\circ}$, heels flat on the ground, and arms crossed across the chest and hands positioned on the shoulders. This constituted the 'down' position. The feet were held to the ground by a test administrator. On the start command, candidates raised their 
shoulders from the ground while keeping their arms crossed, and touched their elbows to their knees. The candidates then descended back down until the shoulder blades contacted the ground. Candidates completed as many repetitions as possible in the allocated $60 \mathrm{~s}$ time period but could rest in the 'down' position. Only full repetitions were counted and only one trial was given.

\section{5-Yard Pursuit Run (75PR)}

The 75PR was designed to simulate a foot pursuit for a LEO (30), and is shown in Figure 1. The candidate in this test completed two trials, and the 75PR involved five linear sprints about a square grid (each side was 12.1 meters [m]), while completing four, $45^{\circ}$ direction changes zig-zagging across the grid. Candidates were also required to step over three barriers that were $2.44 \mathrm{~m}$ long and $0.15 \mathrm{~m}$ high that simulated roadside curbs during three of the five linear sprints. Time was recorded via a stopwatch, from the initiation of movement at the start of the sprint, until the candidates crossed the finish line. Timing via stopwatches is standard practice in LEA testing $(14,30)$. Furthermore, test administrators trained in the use of stopwatch timing procedures for running tests, which the testers were in this study, can record reliable and consistent data (20).

***INSERT FIGURE 1 ABOUT HERE***

\section{Arm Ergometry}

The arm ergometer test was used an assessment of upper-body endurance, and was performed on a standard arm ergometer (Monark 881E, Vansbro, Sweden) positioned on a table, and standard procedures were followed for all candidates with candidates completing only one trial (30). The candidate knelt on a padded mat such that the crankshaft handle was level with the candidate's 
shoulder. The test began from a position where the left arm of the candidate was fully extended and parallel to the ground (30). The candidate completed 10 revolutions of the arm ergometer prior to the test to set the resistance at 50 watts. The counter was set to zero before the test commenced. After the administrator initiated the test, candidates completed as many revolutions as possible in $60 \mathrm{~s}$.

\section{4-km Run}

The 2.4-km run was used to assess aerobic capacity $(14,16,31)$, and was performed using on a 400-m outdoor running track at the training academy for the LEA. Candidates completed six laps around this track as quickly as possible for only one trial. Similar to the required instructions for other LEAs, candidates were instructed to slow their pace if they experienced any pain, severe shortness of breath, or other abnormal signs. The run time was recorded for each candidate on a handheld stopwatch to the nearest $0.10 \mathrm{~s}$, and reported as minutes: seconds (min:s).

\section{Statistical Analyses}

Statistical analyses were processed using the Statistics Package for Social Sciences (Version 24; IBM Corporation, New York, USA), and Microsoft Excel (Microsoft Corporation ${ }^{\mathrm{TM}}$, Redmond, Washington, USA). The sample was stratified by sex (males and females) and age (20-24, 25-29, 30-34, 35-39, and 40+ years of age) $(16,31)$. Descriptive data (mean \pm standard deviation [SD) were calculated for each of these groups. A 2 x 5 univariate analysis of variance (ANOVA) was conducted to (a) determine if there was a significant $(p<0.05)$ interaction between the sexes and (b) determine if there were significant $(p<0.05)$ interactions between the age groups. Levene's test for equality of variances was used to ascertain the homogeneity of variance for the data, with 
significance set as $p<0.05$. If data was found to be heterogeneous, the alpha level required for between-group significant interactions was adjusted to $p<0.01$ to reduce the chance of making a Type I error. The ANOVA analysis was still utilized due to the robustness of these procedures when used with a large sample, even with unequal group sizes which could influence the homogeneity of variance of the data (31). If a significant interaction between the age groups was found, a Bonferroni post hoc adjustment for multiple pairwise comparisons to identify where, if any, significance lay $(p<0.05)$. Effect sizes $(d)$ were also calculated for the between-group comparisons for sex and age, where the difference between the means was divided by the pooled SD (10). A $d$ between 0.2 to 0.6 was considered a small effect; 0.6 to 1.2 a moderate effect; 1.2 to 2.0 a large effect; and 2.0 and above a very large effect (7).

\section{RESULTS}

The data for the male and female groups are shown in Table 1. Homogenous data was indicated for height (Levene statistic $=0.589, p=0.807)$, sit-ups $($ Levene statistic $=1.341, p=0.213)$, arm ergometer test $($ Levene statistic $=1.081, p=0.375)$, and the 75PR $($ Levene statistic $=1.425, p=$ 0.174). The alpha level for significance for these data was set to $p<0.05$. Heterogeneous data was indicated for age $($ Levene statistic $=20.079, p<0.001)$, body mass $($ Levene statistic $=1.989$, $p=0.039)$, push-ups $($ Levene statistic $=2.102, p=0.028)$, and the $2.4-\mathrm{km}$ run $($ Levene statistic $=$

$3.166, p=0.001)$. The alpha level for significance for these data was set to $p<0.01$. There was no significant interaction between the sexes for age $(F=0.290, d f=1, p=0.590)$. There was a significant interaction between the sexes for height $(F=112.402, d f=1, p<0.001)$, body mass $(F$ $=134.540, d f=1, p<0.001)$, push-ups $(F=94.907, d f=1, p<0.001)$, sit-ups $(F=7.352, d f=1$, $p=0.007)$, arm ergometer revolutions $(F=76.883, d f=1, p<0.001), 75 \mathrm{PR}(F=73.425, d f=1$, 
$p<0.001)$, and the $2.4-\mathrm{km} \operatorname{run}(F=14.320, d f=1, p<0.001)$. There were no significant differences in age between the sexes, but males were significantly taller and heavier than females, and both of these comparisons had large effects. The males performed significantly more push-ups, sit-ups, arm ergometer revolutions, and were faster in the $75 \mathrm{AR}$ and $2.4-\mathrm{km}$ run. There were large effects for the differences in the push-up test, 75AR, and arm ergometer test, a moderate effect for the 2.4-km run, and small effect for the sit-up test.

***INSERT TABLE 1 ABOUT HERE***

The data for the different age groups is shown in Table 2, with the effect size data in Table 3. There were no significant interactions for height $(F=1.558, d f=4, p=0.184)$ or body mass $(F$ $=1.462, d f=4, p=0.212$ ) between the age groups. However, the post hoc analyses indicated the 25-29 year group was heavier than the 20-24 year group $(p=0.002)$, although the effect was small. There was a significant interaction between the age groups for the 75PR $(F=6.583, d f=4, p<$ 0.001). Post hoc analyses showed that the 20-24 year ( $p<0.001$; large effect), 25-29 year $(p<$ 0.001; moderate effect), and 30-34 year ( $p=0.003$; moderate effect) groups were all significantly faster in the 75AR when compared to the $40+$ year group. The 20-24 year $(p<0.001$; moderate effect) and 25-29 year ( $p=0.004$; small effect) groups were faster than the 35-39 year group, while the 20-24 year group was also faster than the 30-34 year group ( $p=0.003$; small effect). There was not a significant age group interaction for the 2.4-km run $(F=2.095, d f=4, p=0.080)$. However, post hoc analyses indicated that the 20-24 year group was significantly faster than the $40+$ year group in the $2.4-\mathrm{km}$ run $(p=0.004)$, which had a moderate effect. There were no 
significant interaction between the age groups for the push-up $(F=0.694, d f=4, p=0.660)$, situp $(F=0.700, d f=4, p=0.592)$, and arm ergometer $(F=0.844, d f=4, p=0.498)$ tests.

\section{***INSERT TABLE 2 ABOUT HERE*** \\ ***INSERT TABLE 3 ABOUT HERE***}

\section{DISCUSSION}

The purpose of this study was to examine the effects of sex and age on the physical fitness of LEA candidates within a testing battery conducted during the hiring process prior to entering a 22 -week academy. Recruits are not hired until successful completion and graduation from academy training. Physical fitness is important for a candidate as it can increase their chances of successfully graduating academy (42), while also serving as a foundation for job-specific tasks $(4,15)$. It should be noted that there was a wider range of ages present in the $40+$ year group (candidates ranged from 40 to 56 years of age). However, this is because LEAs cannot discriminate with regards to age when hiring potential candidates (32). Furthermore, a wide range of ages is common in research conducted on law enforcement populations $(6,9,16,29-31,42)$, and is thus typical within these types of analyses. The results from this study indicated that male candidates, in general, performed better than female candidates in all of the fitness tests. In addition to this, younger candidates were faster in the 75PR when compared to older candidates, and the 20-24 year group performed better when compared to the $40+$ year group in the $2.4-\mathrm{km}$ run. These data clearly identify differences in the physical fitness of incoming candidates to a LEA. Further to this, these data support the notion that due to the differences among individuals, utilizing a training program that follows a 'one-size-fits-all' model would not be appropriate for LEA training staff (36) . 
Between-sex comparisons revealed that female candidates, in general, had a lower physical capacity when compared to their male counterparts. Comparisons made for physical capacity of recruits were examined in absolute terms due to recruits needing to complete the same tasks during physical training, regardless of age or sex (36). This is done with the expectation that all candidates with have the same job tasks once they finish academy and begin their occupation (3). Male candidates completed a greater number of push-ups, sit-ups, and arm ergometer revolutions while also recording faster $75 \mathrm{PR}$ and $2.4-\mathrm{km}$ times. These results are not uncommon as it is well documented that males are typically stronger than females in absolute terms $(6,22)$. Yanovich et al. (45) found that differences in aerobic capacity, anaerobic capacity, and upper extremity endurance between males and females could not be bridged during a four-month Army Basic Training (BT) program with males tending to be stronger prior to BT. Furthermore, in a fitness test such as the sit-up, where previous literature has found no differences between the sexes (13), the candidates for this LEA did show significant differences in performance on this measure. The practical applications of these findings for LEA academy training suggests that a more individualized programming could alleviate the potential risk factors of a traditional approach (i.e. musculoskeletal injuries) for candidates with poorer performance (36), which based on this research, may comprise of more female candidates. Female recruits, in particular, were found to be at an increased risk of injury due to inappropriate loading during military training $(2,26)$. Although this potential injury risk cannot be confirmed by the results of this study, and requires further investigation in LEA populations, the females from this study, these findings bear consideration and require further investigation in LEA populations.

The results from this study also indicated that younger candidates tended to perform better in select physical fitness tests when compared to older candidates. For example, three of the 
younger age groups (20-24 years, 25-29 years, and 30-34 years) were significantly faster than the $40+$ age group in the $75 \mathrm{PR}$. The $75 \mathrm{PR}$ was implemented by the staff from this LEA to simulate an officer running to apprehend a suspect, which is an essential job task, and assesses a candidate's change-of-direction (COD) ability (30). COD ability incorporates lower-body strength, power and running speed $(21,44)$. Accordingly, these physical characteristics are essential within the performance of these tests. Traditionally, LEA training staff tend to focus on aerobic conditioning during their academy training, often in the form of long distance runs (8). Long distance runs at a submaximal intensity would not be the most conducive to building the foundational elements (i.e., lower-body strength and power, maximal running speed) necessary for COD ability. Boccia et al. (5) found that after prolonged running, the contractile velocity of the muscle decreased due to muscle fatigue, resulting in an acute strength loss. This is a further issue for older candidates, as there can be a gradual decline in muscle strength of approximately $1-1.5 \%$ per year in adults (33). Even though physical fitness-related declines in performance tend to be shown in much older populations (60-80 years) such as that detailed by Kennis et al. (24), this information still has some practical importance to this study. Strength and power training could still be of benefit to older LEA candidates (40-50 years) during academy due to the prevalence of age-related strength losses that could occur as age increases. This coincides with research done by Knapik et al. (25) showing that muscular and cardiorespiratory endurance declines as age increases when analyzing Army soldiers 18-53 years old. Additionally, implementation of sprint interval training could further develop lower-body strength in candidates (36), which could benefit COD and foot pursuit abilities (43). This is especially important for older candidates, given the importance of foot pursuit ability for all LEOs $(14,31)$. 
A common assessment utilized by LEA staff to measure aerobic capacity is the 2.4-km run $(9,16,31)$. Aerobic conditioning is beneficial to LEOs in that greater aerobic fitness allows officers to perform tasks longer, fatigue less rapidly, and recover faster (23). In the 2.4-km run, the younger candidates (20-24 year group) were significantly faster than the older candidates ( $40+$ year group). This could be partially due to a decrease in contractile tissue and maximum force generation capacity with increased age, which is of importance for maintaining aerobic capacity (33). Previous research also suggests with increased age, power also decreases, which can occur earlier than strength decreases $(28,40)$. Even though the $2.4-\mathrm{km}$ run is primarily an aerobic test, running power can still contribute to superior performance during a longer distance run (12). Due to the disparity of aerobic fitness levels among the candidates, more individual-focused (i.e. abilitybased) training programs would be better suited to allow for all candidates to develop aerobic adaptations. An option that could be of use in developing aerobic capacity, as well as other essential physical characteristics, is interval training. High Intensity Intermittent Training (HIIT) has been shown to develop both strength and power while also developing aerobic capacity (19, 41). Rowan et al. (41) found that implementing HIIT for 25 minutes, two times per week, led to an increase in aerobic capacity in collegiate soccer players while leaving more time for sportspecific drills. HIIT implementation in an academy setting could promote physical fitness in different capacities for all candidates, be more individualized where appropriate, while also allowing for more time to be directed towards job-specific training.

There were no significant differences between the age groups for number of push-ups performed. These findings are consistent with previous research in a law enforcement population. Dawes et al. (13) found that push-up performance did not necessarily deteriorate with age (range 20 to 59 years) in a law enforcement population and may be maintained with increases in 
endurance compensating for increases in any age associated fat mass increases. Likewise, there were no significant differences in sit-ups and arm ergometer revolutions completed. This suggests that performance in these tests could be maintained across younger and older candidates. The physical capacity that these tests primarily assess is strength endurance $(14,30,31)$. Muscular endurance is the muscles ability to sustain prolonged contractions that are less likely to become fatigued, and therefore can provide support over time (35). Regardless of age, the development of strength endurance should be of emphasis in academy training as possible encounters on the job may require them to sustain effort for prolonged periods of time, and could also be indicative of a candidate's ability to graduate academy $(4,42)$.

There were several limitations in this study that should be noted. Only one LEA was analyzed in this study; a variety of agencies should be investigated in future research as research suggest fitness differences exist between candidates from different agencies (34). Maximal strength and power tests were not incorporated in the fitness testing battery for this LEA. A majority of the physical fitness tests administered were primarily aerobic (2.4-km run) or focused more on strength endurance (push-ups, sit-ups and the arm ergometer). Given the importance of strength and power in essential job tasks for LEOs $(12,37)$, future research should assess these qualities in LEA candidates, recruits, and incumbents. There was also a smaller pool of female candidates $(n=84)$, compared to male candidates $(n=432)$, although this is typical for LEAs $(6$, $9,16,29-31,42)$. Although this may skew some of the data (which is a limitation), the value of this research is that the data has been directly taken from candidates that have applied to work for a LEA (i.e. this is a specific law enforcement population). This increases the practical application of this research. This study did not look at injury rates sustained in academy training. However, previous research has found that the factors contributing to increased number of injuries were age 
( $\geq 30$ years), level of physical activity prior to entering academy, and sex - with females having almost double the injury rate than that of their male counterparts during a 10-week Army Basic Combat Training (26). It could be assumed that the females in this study may also have a higher risk of injury if traditional LEA training approaches are followed, although this needs to be confirmed with future research. Nonetheless, within the context of these limitations, the data did suggest that male candidates, in general, performed better than female candidates in all fitness tests, and that younger candidates were generally faster than older candidates in both the $75 \mathrm{PR}$ and 2.4-km run. The results from the current study reinforce the differences in physical fitness that can occur in LEA candidates, and the importance of utilizing an individualized approach to training to optimize fitness improvements and reduce injury risk.

\section{PRACTICAL APPLICATIONS}

The results from this study indicated that female and older LEA candidates could potentially perform poorer during academy training when compared to male and younger LEA candidates. This should be of importance to LEA training staff, as those candidates that demonstrate lower physical fitness could result in higher separation rates within the academy (42). Given the fitness differences that can occur in LEA candidates, training staff should attempt to use a more individualized approach to physical training, with appropriate periodization. A challenge for practitioners and training staff is developing a range of important fitness characteristics in an environment with non-traditional training times and with candidates of varying fitness levels. The implementation of modalities such as HIIT training would allow for the development of running speed and aerobic fitness, which are essential characteristics to job task performance $(4,9,16)$, and can be manipulated according to the ability of candidates. Circuit training could also be of use 
in developing muscular strength in candidates (36), and modified according to the individual. LEA training staff should attempt to ensure strength, power, and aerobic fitness are developed for all law enforcement candidates during academy specific to the job, regardless of sex and age.

\section{REFERENCES}

1. Anderson, MK, Grier, T, Canham-Chervak, M, Bushman, TT, Nindl, BC, and Jones, BH. Effect of Mandatory Unit and Individual Physical Training on Fitness in Military Men and Women AM J Health Promot. 31:378-387. 2017.

2. Bell, NS, Mangione, TW, Hemenway, D, Amoroso, PJ, and Jones, BH. High injury rates among female army trainees: a function of gender? AM J Prev Med. 18:141-146. 2000.

3. Birzer, ML and Craig, DE. Gender differences in police physical ability test performance. Am J Police. 15:93-108. 1996.

4. Bissett, D, Bissett, J, and Snell, C. Physical agility tests and fitness standards: perceptions of law enforcement officers. Police Pract Res. 13:208-223. 2012.

5. Boccia, G, Dardanello, D, Tarperi, C, Rosso, V, Festa, L, La Torre, A, Pellegrini, B, Schena, F, and Rainoldi, A. Decrease of muscle fiber conduction velocity correlates with strength loss after an endurance run. Physiol Meas. 38:233-240. 2017.

6. Boyce, RW, Jones, GR, Schendt, KE, Lloyd, CL, and Boone, EL. Longitudinal changes in strength of police officers with gender comparisons. J Strength Con Res. 23:2411-2418. 2009.

7. Buchheit, M. The numbers will love you back in return-I promise. Int J Sports Physiol Perform. 11:551-4. 2017. 
8. Cesario, KA, Moreno, MR, Bloodgood, AM, Dulla, JJ, and Lockie, RG, Heart rate responses of a custody assistant class to a formation run during academy training in Southwest American College of Sports Medicine's 37th Annual Meeting: Long Beach, CA USA. 2017.

9. Cocke, C, Dawes, J, and Orr, R. The use of 2 conditioning programs and the fitness characteristics of police academy cadets. J Athl Train. 51:887-896. 2016.

10. Cohen, J. Statistical Power Analysis for the Behavioral Sciences 2nd ed. Hillsdale, New Jersey: Lawrence Earlbaum Associates, 1988.

11. Commission of Peace Officers Standards and Training (2018). Physical Ability Testing Information Retrieved January 16, 2019, from https://post.ca.gov/Physical-Ability$\underline{\text { Testing-FAQs }}$

12. Dawes, JJ, Orr, RM, Elder, CL, Krall, K, Stierli, M, and Schilling, B. Relationship between selected measures of power and strength and linear running speed amongst Special Weapons and Tactics police officers. J Aust Strength Cond. 23:23-28. 2015.

13. Dawes, JJ, Orr, RM, Brandt, BL, Conroy, RL, and Pope, R. The effect of age on push-up performance amongst male law enforcement officers. J Aus Strength Cond. 24:23-27. 2016.

14. Dawes, JJ, Orr, RM, Siekaniec, CL, Vanderwoude, AA, and Pope, R. Associations between anthropometric characteristics and physical performance in male law enforcement officers: A retrospective cohort study. Ann Occup Environ Med. 28: doi:10.1186/s40557-016-01125. 2016. 
15. Dawes, JJ, Lindsay, K, Bero, J, Elder, C, Kornhauser, C, and Holmes, R. Physical fitness characteristics of high vs. low performers on an occupationally specific physical agility test for patrol officers. J Strength Cond Res. 31:2808-2815. 2017.

16. Dawes, JJ, Orr, RM, Flores, RR, Lockie, RG, Kornhauser, C, and Holmes, R. A physical fitness profile of state highway patrol officers by gender and age. Ann Occup Environ Med. 29:16. 2017.

17. Decker, A, Orr, RM, Pope, R, and Hinton, B. Physiological demands of law enforcement occupational tasks in Australian police officers. J Aust Strength Cond. 24:78-79. 2016.

18. Heir, T and Eide, G. Injury proneness in infantry conscripts undergoing a physical training programme: smokeless tobacco use, higher age, and low levels of physical fitness are risk factors. Scan J Med Sports. 7:304-311. 1997.

19. Hendrickson, NR, Sharp, MA, Alemany, JA, Walker, LA, Harman, EA, Spiering, BA, Hatfield, DL, Yamamoto, LM, Maresh, CM, Kraemer, WJ, and Nindl, BC. Combined resistance and endurance training improves physical capacity and performance on tactical occupational tasks. Eur J Appl Physiol. 109:1197-208. 2010.

20. Hetzler, RK, Stickley, CD, Lundquist, KM, and Kimura, IF. Reliability and accuracy of handheld stopwatches compared with electronic timing in measuring sprint performance. J Strength Cond Res. 22:1969-1976. 2008.

21. Hori, N, Newton, RU, Andrews, WA, Kawamori, N, Mcguigan, MR, and Nosaka, K. Does performance of hang power clean differentiate performance of jumping, sprinting, and changing of direction? J Strength Con Res. 22:412-418. 2008.

22. Janssen, I, Heymsfield, SB, Wang, Z, and Ross, R. Skeletal muscle mass and distribution in 468 men and women aged 18-88 yr. J Appl Psychol. 89:81-88. 2000. 
23. Jones, A and Carter, $\mathrm{H}$. The effect of endurance training on parameters of aerobic fitness. Sports Medicine 29:373-386. 2000.

24. Kennis, E, Verschueren, SM, Bogaerts, A, Van Roie, E, Boonen, S, and Delecluse, C. Long-term impact of the strength training on muscle strength characteristics in older adults. Arch Phys Med Rehabil. 94:2054-2060. 2013.

25. Knapik, JJ, Banderet, LE, Vogel, JA, Bahrke, MS, and O'connor, JS. Influence of age and physical training on measures of cardiorespiratory and muscle endurance. Eur J Appl Physiol. 72:490-495. 1996.

26. Knapik, JJ, Sharp, MA, M.F., C-C, Hauret, KH, Patton, JH, and Jones, BH. Risk factors of training-related injuries among men and women in basic combat training. Med Sci Sports Exerc. 33:946-954. 2001.

27. Korhonen, MT, Cristea, A, Alen, M, Hakkinen, K, Sipila, S, Mero, A, Vittasalo, JT, Larsson, L, and Suominen, H. Aging, muscle fiber type, and contractile function in sprinttrained athletes. J Appl Psychol. 11:906-917. 2006.

28. Lanza, IR, Towse, TF, Caldwell, GE, Wigmore, DM, and Kent-Braum, JA. Effects of age on human skeletal torque, velocity, and power in two muscle groups. J Appl Physiol. 95:2361-2369. 2003.

29. Lockie, RG, Dawes, JJ, Orr, RM, Stierli, M, Dulla, JM, and Orjalo, AJ. An analysis of the effects of sex and age on upper-and lower-body power for law enforcement agency recruits prior to academy training. J Strength Con Res. 32:1968-1974. 2018.

30. Lockie, RG, Stierli, M, Dawes, JJ, Cesario, KA, Moreno, MR, Bloodgood, AM, and Dulla, JM. Are there similarities in physical fitness characteristics of successful candidates attending law enforcement training regardless of training cohort? J Trainol. 7:5-9. 2018. 
31. Lockie, RG, Dawes, JJ, Kornhauser, CL, and Holmes, RJ. Cross-sectional and retrospective cohort analysis of effects of age on flexibility, strength endurance, lowerbody power, and aerobic fitness in law enforcement officers. J Strength Con Res. 33:451458. 2019.

32. Los Angeles County Sheriff's Department (2016). Physical Ability Test Retrieved March 9, 2017, 2017, from http://lasdcareers.org/physical-ability-test/

33. Macaluso, A and De Vito, G. Muscle strength, power and adaptations to resistance training in older people. Eur J Appl Physiol. 91:450-472. 2004.

34. Myers, C, Orr, R, Goad, K, Schram, B, Lockie, R, Korhonen, C, Holm, R, and Dawes, J, Comparing levels of fitness of police officers between two United States law enforcement agencies, in 3rd International Conference on Physical Employments Standards: Portsmouth, UK 2018.

35. Nesser, T, Huxel, K, Tincher, J, and Okada, T. The relationship between core stability and performance in division I football players. J Strength Con Res. 22:1750-1754. 2008.

36. Orr, RM, Ford, K, and Stierli, M. Implementation of an ability-based training program in police force recruits. J Strength Con Res. 30:2781-2787. 2015.

37. Orr, RM, Pope, R, Peterson, S, Hinton, B, and Stierli, M. Leg power as an indicator of risk of injury or illness in police recruits. Int J Environ Res Public Health. 13: doi:10.3390/ ijerph13020237. 2016.

38. Orr, RM, Pope, R, Stierli, M, and Hinton, B. Grip strength and its relationship to police recruit task performance and injury risk: A retrospective cohort study. Int J Environ Res Public Health. 14: doi:10.3390/ijerph14080941. 2017. 
39. Pate, RR and Kriska, A. A physiological basis of the sex difference in cardiorespiratory endurance. Sports Med. 1:87-98. 1984.

40. Raj, IS, Bird, SR, and Shield, AJ. Aging and the force-velocity relationship of muscles. Exp Gerontol. 45:81-90. 2010.

41. Rowan, AE, Kueffner, TE, and Stavrianeas, S. Short duration high-intensity interval training improves aerobic conditioning of female college soccer players. Int J Exerc Sci. 5:232-238. 2012.

42. Shusko, M, Benedetti, L, Korre, M, Eshleman, EJ, Farioli, A, Christophi, CA, and Kales, SN. Recruit fitness as a predictor of police academy graduation. Occup Med. 67:555-561. 2017.

43. Spiteri, T, Cochrane, JL, Hart, NH, Haff, GG, and Nimphius, S. Effect of strength on plant foot kinetics and kinematics during a change of direction task. Eur J Sport Sci. 13:646-652. 2013.

44. Spiteri, TH, Nimphius, SM, Hart, NU, Specos, CU, Sheppard, JU, and Newton, RU. Contribution of strength characteristics to change of direction and agility performance in female basketball athletes. $J$ Strength Con Res. 28:2415-2423. 2014.

45. Yanovich, R, Evans, R, Israeli, E, Constantini, N, Sharvit, N, Merkel, D, Epstein, Y, and Moran, D. Differences in physical fitness of male and female recruits in gender-integrated Army basic training. Med Sci Sports Exerc. 40:654-659. 2008.

\section{FIGURE LEGEND}

Figure 1: The dimensions for the 75-yard pursuit run in meters $(\mathrm{m} ; \mathrm{A})$ and the running direction (numbered in order; B). The barriers were $2.44 \mathrm{~m}$ long and $0.15 \mathrm{~m}$ high. 
Table 1: Age and test performance (mean $\pm \mathrm{SD}$ ) by successful law enforcement agency candidates stratified by sex in physical fitness assessments (number of push-ups and sit-ups completed in 60 s, time to complete the 75-yard agility run [75AR], number of revolutions completed in a 60-s arm ergometer test, and $2.4 \mathrm{~km}$ run time). Pairwise effect size $(d)$ data are also shown.

\begin{tabular}{cccc}
\hline & Males $(\mathrm{n}=432)$ & Females $(\mathrm{n}=84)$ & $d$ \\
\hline Age (years) & $27.30 \pm 6.17$ & $27.51 \pm 5.72$ & 0.04 \\
Height (m) & $1.76 \pm 0.08$ & $\mathbf{1 . 6 2} \pm \mathbf{0 . 0 7 *}$ & 1.86 \\
Body Mass (kg) & $83.31 \pm 11.57$ & $\mathbf{6 4 . 5 7} \pm \mathbf{8 . 6 9 *}$ & 1.83 \\
No. of Push-ups & $42.94 \pm 12.26$ & $\mathbf{2 3 . 7 0} \pm \mathbf{8 . 7 6 *}$ & 1.81 \\
No. of Sit-ups & $40.35 \pm 9.21$ & $\mathbf{3 6 . 2 1} \pm \mathbf{7 . 2 3} *$ & 0.50 \\
75 PR (s) & $17.22 \pm 1.12$ & $\mathbf{1 8 . 8 1} \pm \mathbf{1 . 2 5} *$ & 1.34 \\
Arm Ergometer (revs) & $131.71 \pm 16.76$ & $\mathbf{1 0 8 . 6 1} \pm \mathbf{1 4 . 1 5 *}$ & 1.49 \\
2.4-km time (min:s) & $12: 43 \pm 1: 41$ & $\mathbf{1 3 : 4 2} \pm \mathbf{1 : 0 2 *}$ & 0.71 \\
\hline
\end{tabular}

* Significantly $(p \leq 0.01)$ different from the males. 
Table 2: Age and test performance (mean \pm SD) by successful law enforcement agency candidates stratified by age (20-24 years, 25 29 years, 30-34 years, 35-39 years, and 40+ years) in physical fitness assessments (number of push-ups and sit-ups completed in $60 \mathrm{~s}$, time to complete the 75-yard agility run [75AR], number of revolutions completed in a 60 -s arm ergometer test, and $2.4 \mathrm{~km}$ run time).

\begin{tabular}{cccccc}
\hline & $\begin{array}{c}20-24 \text { years } \\
(\mathrm{n}=198)\end{array}$ & $\begin{array}{c}25-29 \text { years } \\
(\mathrm{n}=186)\end{array}$ & $\begin{array}{c}30-34 \text { years } \\
(\mathrm{n}=69)\end{array}$ & $\begin{array}{c}35-39 \text { years } \\
(\mathrm{n}=33)\end{array}$ & $\begin{array}{c}40+\text { years } \\
(\mathrm{n}=30)\end{array}$ \\
\hline Age (years) & $22.38 \pm 1.24$ & $26.63 \pm 1.44$ & $31.59 \pm 1.42$ & $36.79 \pm 1.58$ & $44.20 \pm 4.38$ \\
Height (m) & $1.73 \pm 0.09$ & $1.75 \pm 0.09$ & $1.73 \pm 0.09$ & $1.71 \pm 0.09$ & $1.74 \pm 10.78$ \\
Body Mass (kg) & $\mathbf{7 8 . 2 1} \pm \mathbf{1 1 . 9 6} *$ & $82.39 \pm 13.24$ & $78.78 \pm 13.08$ & $81.75 \pm 16.36$ & $82.35 \pm 14.18$ \\
No. of Push-ups & $40.59 \pm 13.46$ & $40.30 \pm 14.24$ & $38.52 \pm 13.69$ & $38.64 \pm 14.41$ & $35.87 \pm 11.45$ \\
No. of Sit-ups & $40.34 \pm 9.96$ & $39.78 \pm 8.43$ & $39.39 \pm 8.10$ & $39.48 \pm 8.38$ & $35.47 \pm 8.50$ \\
75AR (s) & $\mathbf{1 7 . 1 9} \pm \mathbf{1 . 1 9 \S ¥ *}$ & $\mathbf{1 7 . 3 8} \pm \mathbf{1 . 2 8} *$ & $\mathbf{1 7 . 7 5} \pm \mathbf{1 . 1 4 *}$ & $18.11 \pm 1.53$ & $18.61 \pm 1.05$ \\
Arm Ergometer (revs) & $127.96 \pm 16.52$ & $127.44 \pm 19.32$ & $129.65 \pm 17.93$ & $123.91 \pm 20.03$ & $131.57 \pm 23.83$ \\
2.4 km run (min:s) & $\mathbf{1 2 : 3 2} \pm \mathbf{1 : 2 8 *}$ & $12: 57 \pm 1: 51$ & $13: 09 \pm 1: 34$ & $13: 16 \pm 1: 24$ & $13: 38 \pm 1: 16$ \\
\hline
\end{tabular}

$\uparrow$ Significantly $(p<0.05)$ different from the $25-29$ year group.

§ Significantly $(p<0.05)$ different from the 30-34 year group.

$¥$ Significantly $(p<0.05)$ different from the 35-39 year group.

* Significantly $(p<0.05)$ different from the $40+$ year group. 
Table 3: Pairwise effect size data between successful law enforcement agency candidates stratified by age (20-24 years, 25-29 years, 30-34 years, 35-39 years, and >40 years) in height, body mass, the number of push-ups and sit-ups completed in 60 seconds, time to complete the 75-yard agility run (75AR), number of revolutions completed in a 60-second arm ergometer test (arm erg), and 2.4-km run time.

\begin{tabular}{|c|c|c|c|c|c|c|c|c|c|c|}
\hline & $\begin{array}{c}20-24- \\
25-29\end{array}$ & $\begin{array}{c}20-24- \\
30-34\end{array}$ & $\begin{array}{c}20-24- \\
35-39\end{array}$ & $\begin{array}{c}20-24- \\
40+\end{array}$ & $\begin{array}{c}25-29- \\
30-34\end{array}$ & $\begin{array}{c}25-29- \\
35-39\end{array}$ & $\begin{array}{c}25-29- \\
40+\end{array}$ & $\begin{array}{c}30-34- \\
35-39\end{array}$ & $\begin{array}{c}30-34- \\
40+\end{array}$ & $\begin{array}{c}35-39- \\
40+\end{array}$ \\
\hline Height & 0.22 & 0.00 & 0.22 & 0.10 & 0.22 & 0.44 & 0.10 & 0.22 & 0.10 & 0.30 \\
\hline Body Mass & 0.33 & 0.05 & 0.25 & 0.32 & 0.27 & 0.04 & 0.00 & 0.20 & 0.26 & 0.04 \\
\hline Push-ups & 0.02 & 0.15 & 0.14 & 0.38 & 0.13 & 0.12 & 0.34 & 0.01 & 0.21 & 0.21 \\
\hline Sit-ups & 0.06 & 0.10 & 0.09 & 0.53 & 0.05 & 0.04 & 0.51 & 0.01 & 0.47 & 0.48 \\
\hline $75 \mathrm{AR}$ & 0.15 & 0.48 & $0.67 \S$ & $1.27 *$ & 0.31 & 0.52 & $1.05 \S$ & 0.27 & $0.78 \S$ & 0.38 \\
\hline Arm Erg & 0.03 & 0.10 & 0.22 & 0.18 & 0.12 & 0.18 & 0.19 & 0.30 & 0.09 & 0.35 \\
\hline 2.4-km run & 0.25 & 0.41 & 0.51 & $0.81 \S$ & 0.12 & 0.19 & 0.43 & 0.08 & 0.34 & 0.28 \\
\hline
\end{tabular}

* Large effect for the pairwise comparison.

$\S$ Moderate effect for the pairwise comparison. 